\title{
Mechanism of Activation of PKB/Akt by the Protein Phosphatase Inhibitor Calyculin A
}

\author{
Mercedes Pozuelo-Rubio • Nick R. Leslie • \\ Jane Murphy $\cdot$ Carol MacKintosh
}

Published online: 18 August 2010

(C) Springer Science+Business Media, LLC 2010

\begin{abstract}
The protein phosphatase inhibitor calyculin A activates $\mathrm{PKB} / \mathrm{Akt}$ to $\sim 50 \%$ of the activity induced by insulin-like growth factor 1 (IGF1) in HeLa cells promoting an evident increased phosphorylation of Ser473 despite the apparent lack of Thr308 phosphorylation of PKB. Nevertheless, calyculin A-induced activation of PKB seems to be dependent on basal levels of Thr308 phosphorylation, since a PDK1-dependent mechanism is required for calyculin A-dependent PKB activation by using embryonic stem cells derived from PDK1 wild-type and knockout mice. Data shown suggest that calyculin A-induced phosphorylation of Ser473 was largely blocked by LY294002 and SB-203580 inhibitors, indicating that both PI3-kinase/TORC2-dependent and SAPK2/p38dependent protein kinases contributed to phosphorylation of Ser473 in calyculin A-treated cells. Additionally, our results suggest that calyculin A blocks the IGF1-dependent Thr308 phosphorylation and activation of PKB, likely due
\end{abstract}

Electronic supplementary material The online version of this article (doi:10.1007/s12013-010-9101-4) contains supplementary material, which is available to authorized users.

J. Murphy · C. MacKintosh

MRC Protein Phosphorylation Unit, College of Life Sciences,

University of Dundee, Dundee DD1 5EH, Scotland, UK

M. Pozuelo-Rubio ( $\square)$

Centro Andaluz de Biología Molecular y Medicina

Regenerativa, CABIMER (SC4), Americo Vespucio s/n,

41092 Sevilla, Spain

e-mail: merce_pozo@yahoo.es

N. R. Leslie

Division of Molecular Physiology, College of Life Sciences,

University of Dundee, Dundee DD1 5EH, Scotland, UK to an enhanced Ser612 phosphorylation of insulin receptor substrate 1 (IRS1), which can be inhibitory to its activation of PI3-kinase, a requirement for PDK1-induced Thr308 phosphorylation and IGF1-dependent activation of PKB. Our data suggest that PKB activity is most dependent on the level of Ser473 phosphorylation rather than Thr308, but basal levels of Thr308 phosphorylation are a requirement. Additionally, we suggest here that calyculin A regulates the IGF1-dependent PKB activation by controlling the PI3-kinase-associated IRS1 Ser/Thr phosphorylation levels.

Keywords PKB $\cdot$ Akt $\cdot$ Phosphorylation $\cdot$ Protein phosphatase inhibitor

\begin{tabular}{|c|c|}
\hline \multicolumn{2}{|l|}{ Abbreviations } \\
\hline IGF1 & Insulin-like growth factor 1 \\
\hline IRS1 & Insulin receptor substrate 1 \\
\hline MAPKAP-K2 & $\begin{array}{l}\text { Mitogen-activated protein kinase- } \\
\text { activated protein kinase } 2\end{array}$ \\
\hline PKB & $\begin{array}{l}\text { Protein kinase B (also known as } \\
\text { Akt) }\end{array}$ \\
\hline PI3-kinase & Phosphatidylinositide 3-kinase \\
\hline SAPK2 & $\begin{array}{l}\text { Mitogen-activated protein (MAP) } \\
\text { kinase stress-activated protein } \\
\text { kinase-2/p38 }\end{array}$ \\
\hline PDK1 & $\begin{array}{l}\text { Phosphoinositide-dependent kinase- } \\
1\end{array}$ \\
\hline AGC kinase family & $\begin{array}{l}\text { cAMP-dependent protein kinases } \mathrm{A} \text {, } \\
\text { cGMP-dependent protein kinases } \mathrm{G} \\
\text { and phospholipid-dependent protein } \\
\text { kinases } \mathrm{C}\end{array}$ \\
\hline mTOR & Mammalian target of rapamycin \\
\hline TORC2 & Target of rapamycin complex 2 \\
\hline DNA-PK & DNA-dependent protein kinase \\
\hline
\end{tabular}




\section{Introduction}

Protein kinase $\mathrm{B}$ (PKB/Akt) mediates cellular responses to insulin, growth factors and other stimuli, and is deregulated in diseases, including cancer [1-5]. PKB belongs to the AGC protein kinase subfamily and exists in three isoforms $(\alpha, \beta$ and $\gamma ;$ Akt1, 2 and 3$)$ in mammals. In cells stimulated by insulin or by the insulin-like growth factor 1 (IGF1), PKB is activated by a multistep mechanism $[5,6]$. Phosphoinositide 3-kinase (PI3-kinase) generates $\mathrm{PI}(3,4,5) \mathrm{P}_{3}$ at the plasma membrane, which recruits PKB to the plasma membrane and induces a conformational change. PKB then becomes phosphorylated by phosphoinositide-dependent kinase-1 (PDK1) on a threonine residue (Thr308 in PKB $\alpha$ / Thr309 in $\operatorname{PKB} \beta$ ) in the activation loop of the catalytic domain, while a distinct kinase phosphorylates Ser473 (in $\operatorname{PKB} \alpha$ ) within a hydrophobic motif (HM) in the C-terminal region. While the molecular identity of the Ser473 kina$\mathrm{se}(\mathrm{s})$ is still under investigation, recent evidence suggests that a rapamycin-insensitive form of mammalian target of rapamycin (mTOR), in a complex (termed TORC2) with proteins including Rictor and $\mathrm{G} \beta \mathrm{L}$, mediates phosphorylation of Ser473 in response to insulin and IGF1 [7]. Several other kinases, including mitogen-activated protein kinase-activated protein kinase 2 (MAPKAP-K2) and DNA-dependent protein kinase (DNA-PK), can phosphorylate Ser473 in vitro $[8,9]$. MAPKAP-K2 cannot be the insulin-responsive PDK2 however, because phosphorylation of Ser473 by MAPKAP-2 is independent of 3-phosphorylated inositol lipids, and the drug SB-203580 prevents activation of MAPKAP-K2 but does not block insulin-stimulated phosphorylation of Ser473 in vivo [8]. Many experiments indicate that phosphorylation of Thr308/309 by PDK1 is a requirement for activation of $\mathrm{PKB}$. For example, $\mathrm{PKB} \alpha$ is neither activated nor phosphorylated on Thr308 in response to IGF1 in PDK $1^{-/-}$ mouse embryonic stem (ES) cells [10].

We were therefore surprised to find that when serumdeprived HeLa cells were treated with calyculin A or okadaic acid, two potent inhibitors of PP1, PP2A and related protein (serine/threonine) phosphatases, PKB became highly phosphorylated at Ser473 and was activated, even though there appeared to be only basal levels of Thr308 phosphorylation. Similarly, it had been reported previously that $\mathrm{PKB}$ was activated by tumour necrosis factor alpha (TNF $\alpha)$ in WEHI-164 cells by a mechanism involving phosphorylation of Ser473 but not Thr308 [11], and lithium activated PKB in neurons, apparently with no phosphorylation of Thr308 [12]. How could these absences of Thr308 phosphorylation be reconciled with the essential role of PDK1-catalysed phosphorylation of Thr308 for activation of PKB by insulin and IGF1 [13]? Here, the conundrum of how calyculin $\mathrm{A}$ activates $\mathrm{PKB}$ was dissected further in HeLa cells, and wild-type and $\mathrm{PDK}^{-l-}$ knockout mouse ES cells.

Our data suggest that stoichiometric phosphorylation of Ser473, with a phosphorylation basal of Thr308, supports activation of PKB in calyculin A-stimulated cells. Meanwhile in IGF1-stimulated cells, calyculin A decreases the IGF1-dependent Thr308 phosphorylation and activation of $\mathrm{PKB}$, likely by inducing Ser/Thr phosphorylation of Insulin receptor substrate 1 (IRS1), which desensitizes the IGF1dependent stimulation of PKB.

\section{Materials and Methods}

Materials

Calyculin A, SB-203580, rapamycin and LY294002 were from Calbiochem (CN Biosciences, UK), U0126 was from Promega, IGF1 was from Life Technologies. Tissue culture reagents and pre-poured Novex gels were from Invitrogen, and protein G-Sepharose and activated $\mathrm{CH}$-Sepharose were from Amersham Pharmacia Biotech.

\section{Antibodies}

Antibodies that recognise p70-S6 kinase (isoform 1) and residues $466-480$ of PKB $\alpha /$ Akt1 (PKB total on western blots) were described previously [13, 14]. Antibodies against phospho-FKHRL1(FOXO3a) (pThr32) were from Millipore. Antibodies against phospho-PKB (pSer473; product 9271), phospho-PKB (pThr308; product 9275), phospho-GSK-3 $\alpha / \beta$ (pSer21/9), phospho-p70-S6 kinase (pThr412), p44/p42 MAPK (pThr202/pTyr204), phosphop38 MAPK (pThr180/pTyr182), phospho-IRS1 (pSer612) and total anti-IRS1 were from Cell Signaling Technology. Antibodies that immunoprecipitate $\operatorname{PKB} \alpha$ were purified by standard procedures in MRC Protein Phosphorylation Unit. Antibodies that immunoprecipitate PDK1 and MAPKAP-K2 were previously described $[15,16]$. Secondary antibodies coupled to horseradish peroxidase were from Promega. All antibodies were used according to manufacturers' recommendations.

\section{Cell Culture, Stimulation and Cell Lysis}

HeLa cells were maintained in Dulbecco's modified Eagle's medium (DMEM) supplemented with $10 \%$ (by vol.) foetal bovine serum in a $5 \% \mathrm{CO}_{2}$ humidified incubator at $37^{\circ} \mathrm{C}$. PDK $1^{+/+}$and $\mathrm{PDK} 1^{-1-}$ mouse ES cells were generated and maintained as described [13]. Verification of the identity of cell lines was performed [17]. The cells were either kept in DMEM/serum until harvesting, or transferred to serum free DMEM for $3 \mathrm{~h}$ (HeLa cells), or 
$2 \mathrm{~h}\left(\mathrm{PDK}^{+/+}\right.$and $\mathrm{PDK}^{-/-}$ES cells). Where added, calyculin A $(200 \mathrm{nM})$ was included throughout the period of serum starvation or for the equivalent time in serumcontaining medium. Where included, IGF1 $(100 \mathrm{ng} / \mathrm{ml})$ was added to serum-starved cells for $15 \mathrm{~min}$. Where indicated the following inhibitors of protein kinases were added to serum-starved cells, for an additional $60 \mathrm{~min}$ : LY294002 $(100 \mu \mathrm{M})$, U0126 $(10 \mu \mathrm{M})$, SB-203580 $(10 \mu \mathrm{M})$. Rapamycin was included for $30 \mathrm{~min}(100 \mathrm{nM})$.

Cells were extracted in lysis buffer comprising $50 \mathrm{mM}$ Tris (pH 7.5), 1 mM EDTA, 1 mM EGTA, $1 \%$ (v/v) Triton $\mathrm{X}-100,10 \mathrm{mM} \beta$-glycerophosphate, $50 \mathrm{mM}$ sodium fluoride, $1 \mathrm{mM}$ sodium orthovanadate, $5 \mathrm{mM}$ sodium pyrophosphate, $0.27 \mathrm{M}$ sucrose, $1 \mathrm{mM}$ benzamidine, $0.2 \mathrm{mM}$ PMSF, $10 \mu \mathrm{g} / \mathrm{ml}$ leupeptin and $0.1 \%$ (by vol.) 2-mercaptoethanol. Lysates were centrifuged at $13,000 \mathrm{~g}$ for $10 \mathrm{~min}$ at $4^{\circ} \mathrm{C}$. The supernatants were snap frozen and stored at $-80^{\circ} \mathrm{C}$ until use. Protein concentrations were determined by the Bradford method using bovine serum albumin as standard.

Activities of Protein Kinases that were Immunoprecipitated from Cell Lysates

Thawed lysates (300 $\mu \mathrm{g}$ protein) were clarified by centrifugation and PDK1 was immunoprecipitated by an established procedure [13]. PKB was immunoprecipitated from lysates (200 $\mu \mathrm{g}$ protein) with $10 \mu \mathrm{g}$ antibody coupled to $10 \mu 1$ protein G-Sepharose, and PKB activity in immunoprecipitates was assayed [14]. The activity of MAPKAP-K2 was assayed as described previously [18]. In vitro assays of PI3-kinase broadly followed the method previously described [19]. For all kinases, one unit was the amount that catalysed the phosphorylation of $1 \mathrm{nmol}$ substrate in $1 \mathrm{~min}$.

\section{Statistical Analysis}

Independent experiments were pooled when the coefficient of variance could be assumed identical. Statistical significance was evaluated by using $t$-test Student $(n=$ number of experiments). $P$ values of under 0.05 were considered significant.

\section{Results and Discussion}

$\mathrm{PKB} \alpha$ in Calyculin A-Treated Cells is Recognised by Phosphospecific pSer473-PKB $\alpha$ Antibodies

Using a phospho-specific pSer473-PKB $\alpha$ antibody, we found that calyculin A prevented dephosphorylation of Ser473 of endogenous $\mathrm{PKB} \alpha$ when HeLa cells were

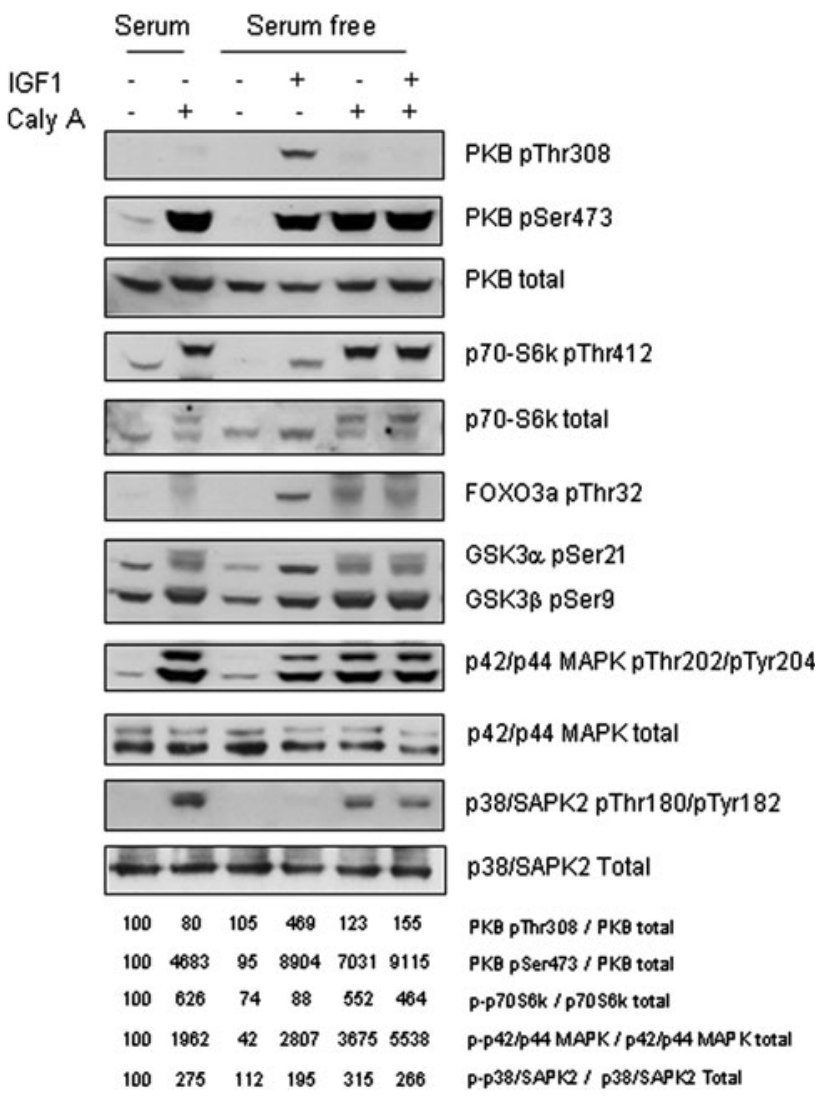

Fig. 1 Calyculin A-treated HeLa cells promote an increased phosphorylation of Ser473 in $\operatorname{PKB} \alpha$. HeLa cells grown in serum were treated with calyculin A ( $200 \mathrm{nM})$ for $3 \mathrm{~h}$, or transferred to serum free medium for $3 \mathrm{~h}$ while treated with or without calyculin A $(200 \mathrm{nM})$. Where indicated, cells were stimulated with IGF1 $(100 \mathrm{ng} / \mathrm{ml})$ for 15 min prior to harvesting. Protein lysates were resolved on $10 \%$ SDS-PAGE gels, transferred to nitrocellulose membranes and probed with indicated antibodies. This is a representative blot of similar experiments run in duplicate. Densitometrical analysis was performed and calculation of phospho/total ratios of the different kinases was performed

transferred from serum-containing to serum free medium (Fig. 1). Consistent with previous reports [20, 21], calyculin A by itself promoted strong phosphorylation of Ser473 in serum free medium in the absence of other inducers (Fig. 1). Similarly, calyculin A stimulated the phosphorylation of p70-S6 kinase at Thr412, which lies in a hydrophobic region and is analogous to Ser473 in PKB $[5,22]$.

The Calyculin A-Induced Phosphorylation of Ser473 on $\mathrm{PKB} \alpha$ is Inhibited by Both LY294002 and SB-203850

The strong phosphorylation of Ser473 of PKB could be because calyculin A blocks a protein phosphatase that dephosphorylates this site. However, while PP2A can dephosphorylate pSer473 in vitro [23], other findings 
indicate that pSer473 is dephosphorylated by a PH-domain containing protein phosphatase (PHLPP) belonging to the calyculin A-insensitive PPM class of PP2C-related enzymes [24]. It is possible that the PHLPP is indirectly inhibited by calyculin A. In any case, the Ser473 kinase(s) would have to be at least slightly active for calyculin A to induce an accumulation of phosphate on this site.

To identify the kinase(s) responsible for phosphorylating Ser473 in calyculin A-treated cells, we preincubated the cells with protein kinase inhibitors before adding calyculin A to the cell medium. The inhibitor of PI3kinase/Akt/mTOR signalling, LY294002 [25], largely inhibited the calyculin A-stimulated phosphorylation of Ser473, consistent with the calyculin A-induced phosphorylation of Ser473 this being at least partially dependent on the activity of a kinase downstream of PI3-kinase, presumably target of rapamycin complex 2 (TORC2) (Fig. 2a).

SB-203580, a specific inhibitor of SAPK2/p38 $\alpha / \beta$ [26], also partially blocked the calyculin A-induced phosphorylation of Ser473 (Fig. 2a). Calyculin A promoted the phosphorylation of SAPK $2 / \mathrm{p} 38 \alpha / \beta$ at sites whose phosphorylation is required for activation, namely Thr 180 and Tyr182 (Fig. 1), and also activated MAPKAP-K2, which is downstream of SAPK2/p38 (data not shown). These findings indicate that SAPK2/p38 $\alpha / \beta /$ MAPKPAP-K2 pathway also contributes to the calyculin A-activation of $\mathrm{PKB}$, consistent with previous reports of okadaic acid-stimulated activation of MAPKAP-K2 [27] and that MAPKAP-K2 can phosphorylate Ser473 of PKB in vitro [28-30].

Neither rapamycin, which targets certain forms of mTOR [31], nor U0126, which inhibits the activation of the mitogen-activated protein kinase (MAPK/ERK) [32], affected Ser473 phosphorylation (Fig. 2a), though calyculin A promoted phosphorylation and activation of MAPK (Fig. 1 and data not shown). In term of comparison, IGF1dependent phosphorylation of PKB in the presence of these inhibitors has been included in supplementary information (Supplementary Fig. 1).

Calyculin A also promoted the activation of PKB in HeLa cells, albeit to a lesser extent than IGF1 (Figs. 2b, 3). Similar to the Ser473 phosphorylation, the calyculin A-induced activation of PKB was partially blocked by LY 294002, and partially by SB-203580 (Fig. 2b), confirming contributions of PI3-kinase- and SAPK2/p38-dependent kinases. LY294002 and SB-203580 together did not completely block calyculin A-induced phosphorylation of Ser473 (not shown) and activation of PKB (Fig. 2b), however, indicating that a third kinase pathway might contribute to phosphorylation of this site in calyculin A-treated cells. In contrast, the calyculin A-induced phosphorylation of p70-S6 kinase on Thr412 and activation of this enzyme were both completely blocked by LY294002 a

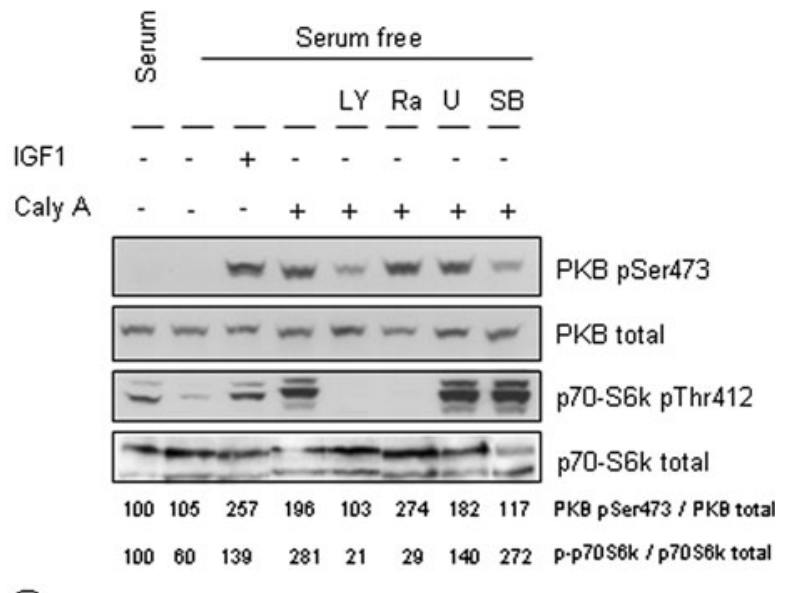

b

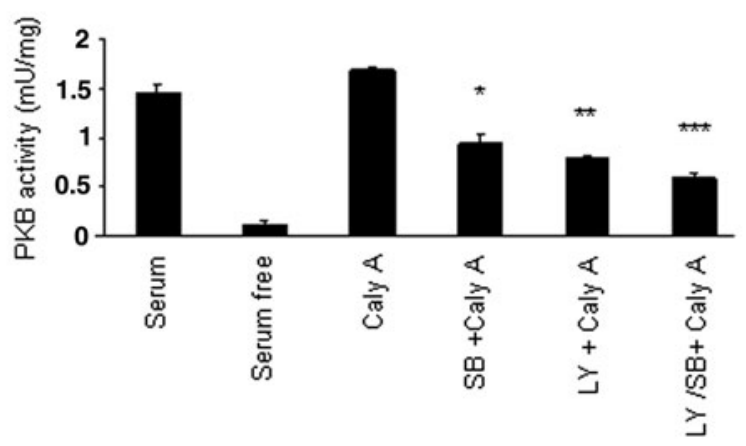

C

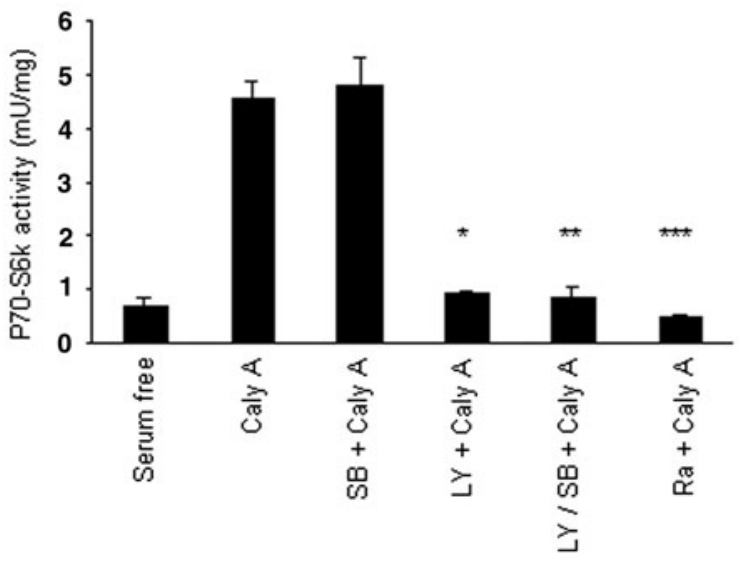

Fig. 2 SB-203580 and LY294002 partially inhibit the calyculin A-induced PKB activation and Ser473 phosphorylation. HeLa cells were transferred to serum free medium and where indicated treated with IGF1 $(100 \mathrm{ng} / \mathrm{ml})$ for $15 \mathrm{~min}$ prior to harvesting. Additionally, the following inhibitors of protein kinases were added for an additional $1 \mathrm{~h}$ : LY294002 (100 $\mu \mathrm{M})$, U0126 (10 mM), SB-203580 $(10 \mu \mathrm{M})$, whereas rapamycin $(100 \mathrm{nM})$ was added for $30 \mathrm{~min}$. Thereafter, calyculin A $(200 \mathrm{nM})$ was added for a further $30 \mathrm{~min}$, and cells were lysed. a Protein lysates ( $25 \mu \mathrm{g}$ protein) were separated on 10\% SDS-PAGE gels, transferred to nitrocellulose membranes and probed with indicated antibodies. $\mathbf{b}$ The cells were lysed, and $\operatorname{PKB} \alpha$ was immunoprecipitated from the lysates and assayed. Activities are the average $\pm \mathrm{SD}(n=3, * P=0.004, * * P=0.00065$, *** $P=$ 0.00067 , Student $t$-test). c The cells were lysed, and p70-S6 kinase was immunoprecipitated from the lysates and assayed. Activities are the average $\pm \mathrm{SD}(n=3, * P=0.0045, * * P=0.0065$, *** $P=$ 0.0024 , Student $t$-test). Densitometrical analysis was performed and calculation of phospho/total ratios of the different kinases was performed 


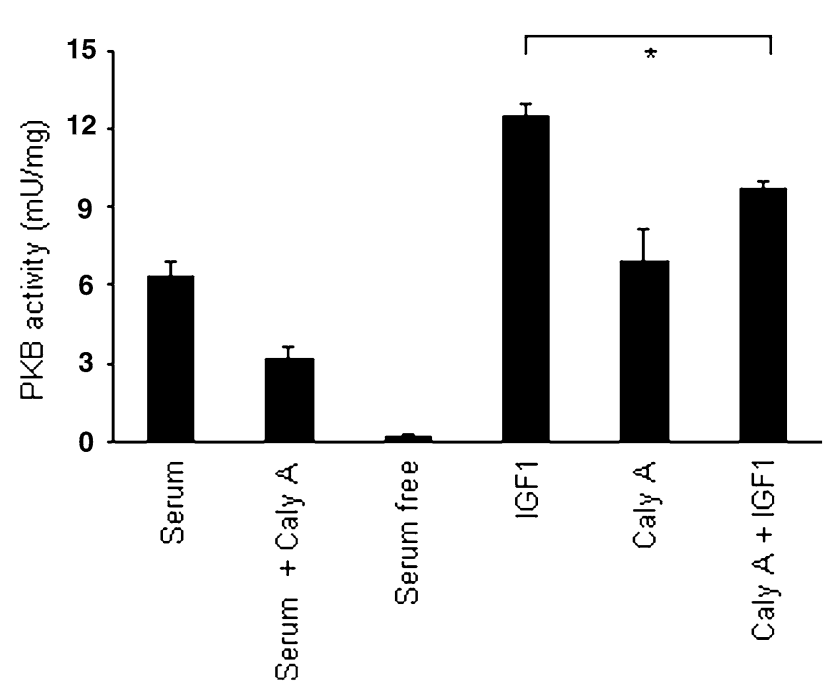

Fig. 3 Calyculin A promotes $\operatorname{PKB} \alpha$ activation. HeLa cells grown in serum were incubated for $3 \mathrm{~h}$ in the absence (Serum) or presence of $200 \mathrm{nM}$ calyculin A (Serum + Caly A). HeLa cells transferred to serum free medium for $3 \mathrm{~h}$ were incubated with calyculin A (Caly A) (200 nM for $3 \mathrm{~h})$, IGF1 (IGF1) (100 ng/ml for $15 \mathrm{~min}$ ) or both (Caly $A+I G F 1)$ as indicated. The cells were lysed, and $\operatorname{PKB} \alpha$ was immunoprecipitated from the lysates and assayed. Activities are the average $\pm \mathrm{SD}(n=3, * P=0.035$, Student $t$-test $)$

and rapamycin (Fig. 2c), and were therefore PI3-kinase/ mTOR dependent. However, SB-203580 did not block either calyculin A-induced Thr412 phosphorylation or activation of p70-S6 kinase indicating that these events are independent of SAPK2/p38-dependent kinases. These data support a previous report suggesting that zinc sulphate activates PI3-kinase, MAPK, JNK, SAPK2/p38 and p70-S6 kinase in neurons, the stimulation of p70-S6 kinase phosphorylation being mainly dependent on rapamycin and LY294002 inhibitors [33]. Some years ago, a report suggested that calyculin A prevented both rapamycin- and sorbitol-mediated deactivation of p70-S6 kinase; thus, it was suggested that osmotic stress and rapamycin act through a calyculin A-sensitive phosphatase to cause dephosphorylation and deactivation of p70-S6 kinase [34]. Additionally, other reports suggest that a calyculin A-sensitive phosphatase is required for the rapamycin- or amino acid deprivation-induced dephosphorylation of p70-S6 kinase, showing a direct protein phosphatase-2A $(\mathrm{PP} 2 \mathrm{~A}) / \mathrm{p} 70-\mathrm{S} 6$ kinase interaction; furthermore, the inactivation of p70-S6 kinase activity through a PP2A-dependent mechanism leads to the inhibition of protein synthesis in endothelial cells $[35,36]$.

Calyculin A Promotes Phosphorylation of GSK- $3 \alpha$, GSK- $3 \beta$ and FOXO3a

Calyculin A induced phosphorylation of GSK- $3 \alpha$, GSK- $3 \beta$ and FOXO3a on sites that are known to be phosphorylated by PKB in response to IGF1 (Fig. $1[37,38]$ ). FOXO3a ran as an upwards smear on the western blot of the calyculin A-treated samples, probably indicative of multiple phosphorylations of this protein. The ubiquitously expressed protein GSK-3 is constitutively active; however, its activity is markedly diminished following phosphorylation of Ser2 1 of GSK $3 \alpha$ and Ser9 of GSK3 $\beta$ by PKB, while dephosphorylation events mediated by $\mathrm{C}(2)$-ceramide ( $N$-acetyl-sphingosine)-dependent stimulation of PP2A promotes GSK3 activation [39]. Phosphorylation of GSK- $3 \alpha$, GSK- $3 \beta$ and FOXO3a are consistent with PKB being active in these cells.

PKB in Calyculin A-Treated Cells was not Recognised by $\mathrm{pThr} 308-\mathrm{PKB} \alpha$ Antibodies

Despite the strong phosphorylation of Ser473 and activation of PKB that were induced by calyculin A, only a basal level of Thr308 phosphorylation of PKB in the calyculin A-treated HeLa cells was detected using the pThr308$\operatorname{PKB} \alpha$ phospho-specific antibody (Figs. 1, 2b, 3). When HeLa cells were transferred to serum free medium, stimulation with calyculin A activated PKB to $\sim 50 \%$ of that induced by IGF1, which was about the same activity as seen when the cells were growing continuously in serum (Fig. 3). Furthermore, PKB activity in cells treated with both IGF1 and calyculin A was about the same as in cells exposed to calyculin A alone, showing a marked decrease in Thr308 phosphorylation compared with IGF1 stimulation alone (Figs. 1, 3). Thus, the calyculin A-induced PKB activation was accompanied by a strong phosphorylation of Ser473, while calyculin A apparently blocked the IGF1dependent Thr308 phosphorylation (Fig. 1). Additionally, the observation that calyculin A suppressed serum-induced PKB activity could be explained because calyculin A may block the Thr308 phosphorylation and PKB activation in response to growth factors present in serum-containing media at the same levels as calyculin A reduces the Thr308 phosphorylation and activation of PKB in response to IGF1. Furthermore, the fact that calyculin A used in serum free media promotes an increased PKB activation than in serum stimulated cells is intriguing, nevertheless our feelings points to a fast inactivation of the serum-dependent Thr308 phosphorylation mediated by calyculin A. This can be reflected by quickly promoting a decreased PKB activity compared with that found in cell stimulated with calyculin A in serum free medium.

Similar findings have been reported for PKB in calyculin A-treated 3T3-L1 cells recognised by the pSer473$\operatorname{PKB} \alpha$, but not by the pThr308-PKB $\alpha$ antibody [20, 21]. Calyculin A and okadaic acid prevented the phosphorylation of Thr308 in response to the cytokine granulocytemacrophage colony-stimulating factor, but did not inhibit 
Ser473 phosphorylation [40]. However, our results are in contrast with those of Yamada et al [41] who reported that calyculin A prolonged the insulin-stimulated phosphorylation of Thr308 in Chinese hamster ovary cells.

That calyculin A-triggered activation of PKB in the apparent basal level of Thr308 phosphorylation was puzzling, given that phosphorylation of Thr308 of PKB by PDK1 has been reported many times to be mandatory for activation of PKB $[8,10,42]$.

$\mathrm{PKB} \alpha$ is not Activated by Calyculin A in $\mathrm{PDK} 1^{-/-}$ES Cells

The possibility that activation of $\mathrm{PKB} \alpha$ by calyculin A does not require PDK1 and phosphorylation of Thr308 was ruled out when we examined phosphorylation and activity of $\mathrm{PKB}$ in response to calyculin $\mathrm{A}$ in $\mathrm{PDK} 1^{+/+}$and $\mathrm{PDK} 1^{-/-}$ mouse ES cells [10] (Fig. 4). As expected [10], PKB was activated, and Thr308 and Ser473 phosphorylated in response to IGF1 in $\mathrm{PDK}^{+/+}$cells (Fig. 4), whereas in $\mathrm{PDK}^{-1-}$ cells, IGF1 stimulated Ser473 phosphorylation

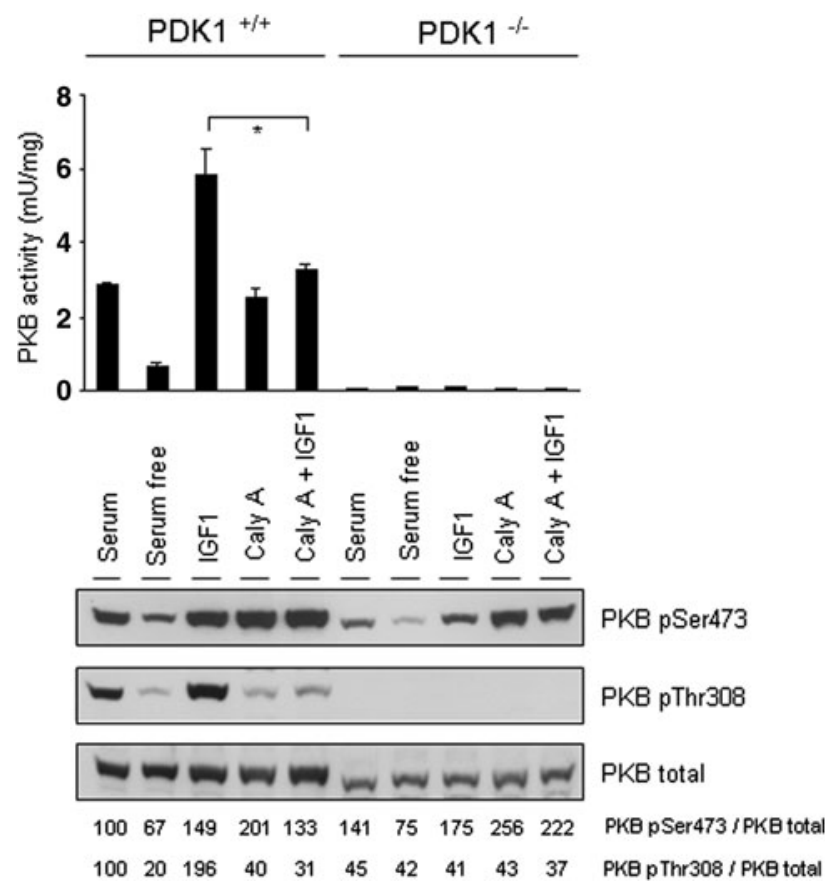

Fig. $4 \mathrm{PKB} \alpha$ is not activated by calyculin $\mathrm{A}$ in PDK $1^{-1-}$ mouse ES cells. PDK $1^{+/+}$and PDK $1^{-/-}$ES cells were grown in the presence of serum (Serum). Some cells were transferred into serum free medium for $2 \mathrm{~h}$, in the absence (Serum free) or presence of $200 \mathrm{nM}$ calyculin A $($ Caly $A)$, and where indicated cells were incubated for $15 \mathrm{~min}$ in the presence of $100 \mathrm{ng} / \mathrm{ml}$ IGF1. The cells were lysed, and PKB $\alpha$ was immunoprecipitated from the lysates and assayed. Activities are the average $\pm \mathrm{SD}(n=3, * P=0.03$, Student $t$-test $) . \quad$ In addition, protein lysates were separated on $10 \%$ SDS-PAGE gels, transferred to nitrocellulose membranes and probed with indicated antibodies. Densitometrical analysis was performed and calculation of phospho/ total ratios of the different kinases was performed but failed to induce Thr308 phosphorylation or PKB activation (Fig. 4). It is interesting to mention that the total PKB was much less in the PDK $1^{-/-}$than in $\mathrm{PDK} 1^{+/+}$ES cells probably due to the lack of PDK1 which may affect in some way the expression levels of PKB.

Similarly to HeLa cells, calyculin A promoted an active PKB induced to $\sim 50 \%$ of that induced by IGF1 in PDK $1^{+/+}$ ES cells, which was about the same activity as seen when the cells were growing continuously in serum. According to data obtained in HeLa cells (Fig. 3), PKB activity in PDK $1^{+/+}$ES cells treated with both IGF1 and calyculin A was about the same as that in cells exposed to calyculin A alone (Fig. 4), while a strong phosphorylation of Ser473 is observed and a marked decreased of Thr308 phosphorylation compared with IGF1 stimulation alone. For comparison, note that while PKB activity in calyculin A-treated cells was similar to that in serum-grown cells, the pThr308$\mathrm{PKB} \alpha$ immunoreactivity of calyculin A-induced PKB was markedly less than that extracted from serum-grown cells (Fig. 4). These data suggest that an increased phosphorylation of Ser473 under basal levels of Thr308 phosphorylation may support similar levels of PKB activation to those found under physiological serum-growth conditions. Nevertheless, despite the apparent extremely low Thr308 phosphorylation, the activation of PKB by calyculin A cannot be entirely due to the Ser473 phosphorylation, because PDK1 is a requirement. Thus, the traces of Thr308 phosphorylation seem to be needed because no PKB activity was seen in the calyculin A-treated PDK1 ${ }^{-1-}$ cells, even showing strong Ser473 phosphorylation levels (Fig. 4).

Calyculin A Promotes Ser612 Phosphorylation of IRS1 and Inhibits IGF1-Stimulated IRS1-Associated PI3-kinase

When IGF1 and calyculin A were tested in combination, the activation of PKB was no higher than that promoted by the protein phosphatase inhibitor alone (Figs. 3, 4). Similarly, Schubert et al [40] reported that okadaic acid activated $\mathrm{PKB}$ and prevented any additional activation in response to cytokine granulocyte-macrophage colonystimulating factor in TF-1 cells. To understand why calyculin A blocked any further activation of PKB by IGF1, the enzymes PDK1 and PI3-kinase in the pathway by which IGF1 activates PKB were assayed.

PDK1 activity was found to be similar in extracts of unstimulated cells, serum-grown cells and IGF1- and calyculin A-treated HeLa cells (Fig. 5) consistent with proposals that PDK1 is constitutively active, and is targeted to $\mathrm{PKB}$ when both protein kinases are recruited to the plasma membrane by 3-phosphorylated inositol lipids generated by PI3-kinase. 


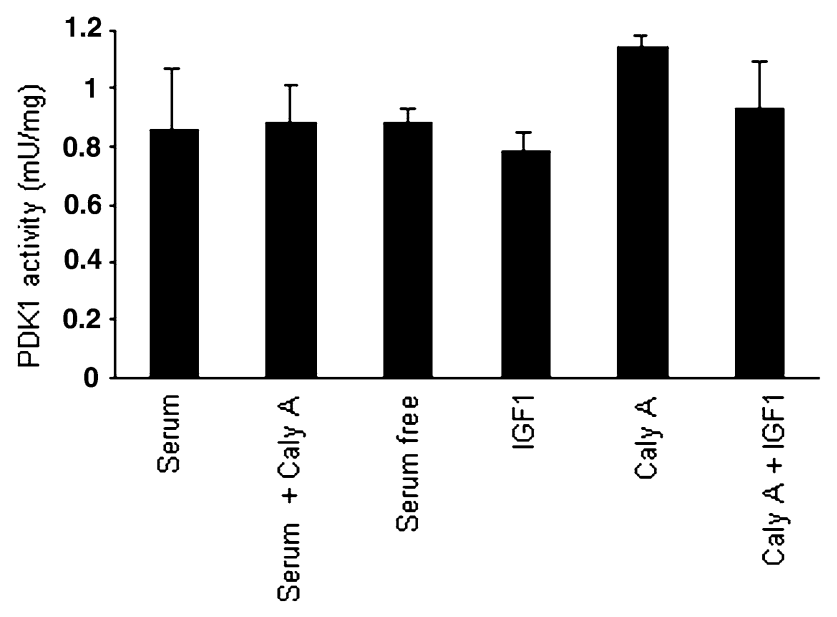

Fig. 5 Calyculin A does not affect extractable PDK1 activity. HeLa cells grown in serum were incubated for $3 \mathrm{~h}$ in the absence (Serum) or presence of $200 \mathrm{nM}$ calyculin A (Serum + Caly A), or were transferred to serum free medium for $3 \mathrm{~h}$ and stimulated in the absence (Serum free) or presence of calyculin A (Caly A) $(200 \mathrm{nM}$ for $3 \mathrm{~h})$, IGF1 (IGF1) $(100 \mathrm{ng} / \mathrm{ml}$ for $15 \mathrm{~min})$ or both $($ Caly $A+I G F 1)$. The cells were lysed and PDK1 was immunoprecipitated from the lysates and assayed. Activities are the average $\pm \mathrm{SD}, n=3$

Fig. 6 Calyculin A increases Ser612 phosphorylation of IRS1. HeLa cells grown in serum were incubated with calyculin A (200 nM) $($ Serum + Caly A) for indicated times (a) or during $3 \mathrm{~h}$ for shown concentrations (c). HeLa cells transferred to serum free medium for $3 \mathrm{~h}$ were incubated with calyculin A (200 nM) (Serum free + Caly A) for indicated times (b) or for $3 \mathrm{~h}$ for shown concentrations $(\mathbf{d})$.

Protein lysates were resolved on $10 \%$ SDS-PAGE gels,

transferred to nitrocellulose membranes and probed with indicated antibodies.

Densitometrical analysis was performed and calculation of phospho/total ratios of the different kinases was performed
PI3-kinase is activated in cells when its regulatory subunit binds to phosphotyrosine residues of activated growth factor receptors or adaptor proteins, such as the insulin receptor substrate (IRS) proteins [43-45]. A decade ago, it was suggested that TNF $\alpha$ is a mediator of insulin resistance in infection, tumour cachexia and obesity by IRS1 phosphorylation on serine residues, and this increased serine phosphorylation interferes with insulin-induced tyrosine phosphorylation of IRS1 and impairs insulin action [46]. Recently, previous works analysing the role of serine phosphorylation of IRS1 in mediating fat-induced insulin resistance, in mice skeletal muscle in vivo, the mutation of IRS1 Ser612 to alanine protected from fatinduced insulin resistance showing the important role of Ser612 phosphorylation of IRS1 in mechanisms of insulin resistance [47]. Thus, aimed at analysing the implication of Ser phosphorylation of IRS1 in the process by which calyculin A decreased the IGF1-dependent Thr308 phosphorylation and activation of PKB, levels of Ser612 phosphorylation were analysed in HeLa cells stimulated with calyculin A. The results suggest that calyculin A

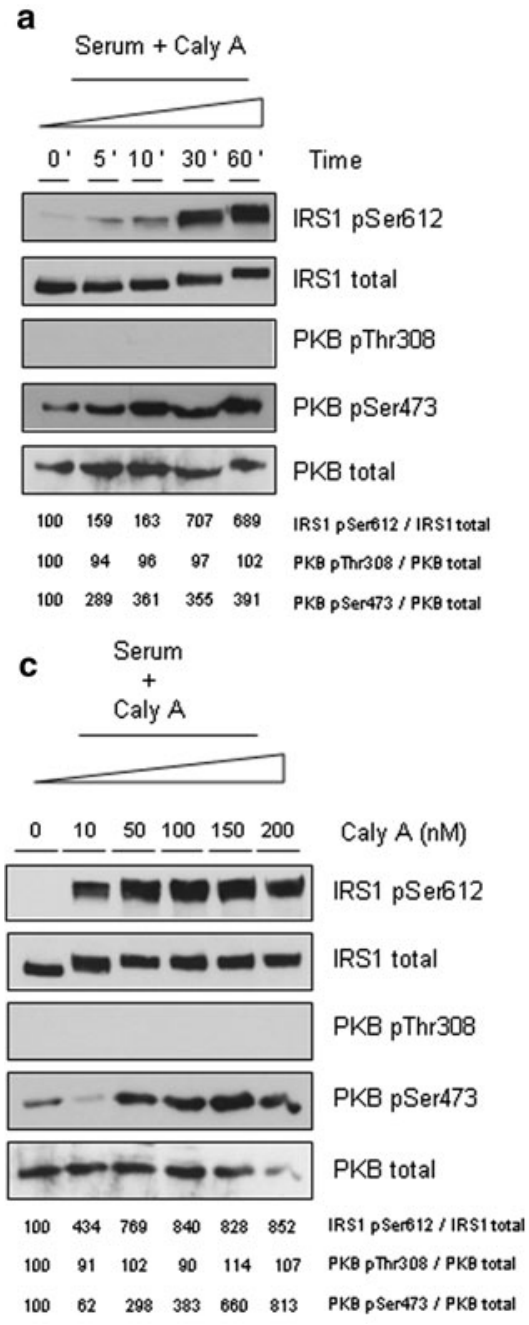

b
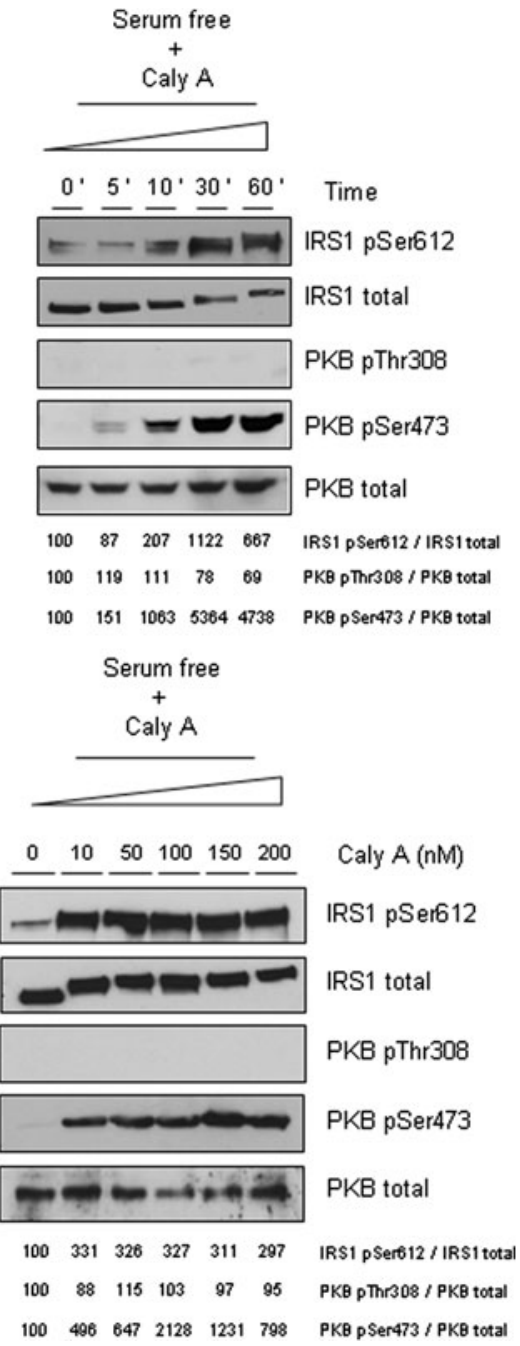
promotes phosphorylation of Ser612 of IRS1 in a dose and time-dependent manner (Fig. 6). Furthermore, phosphorylation of Ser612 of IRS1 was also evident during IGF1 treatment in the presence of calyculin A (Fig. 7).

Stimulation of cells with IGF1 induced a 32-fold increase in IRS1-associated PI3-kinase activity, which was strongly blocked by calyculin A (Fig. 7). In addition, calyculin A blocked the basal PI3-kinase activity associated with IRS1. These findings with calyculin A are consistent with serine/threonine phosphorylation of IRS1 preventing recruitment of PI3-kinase, which has been discovered in normal physiological regulation and in disease

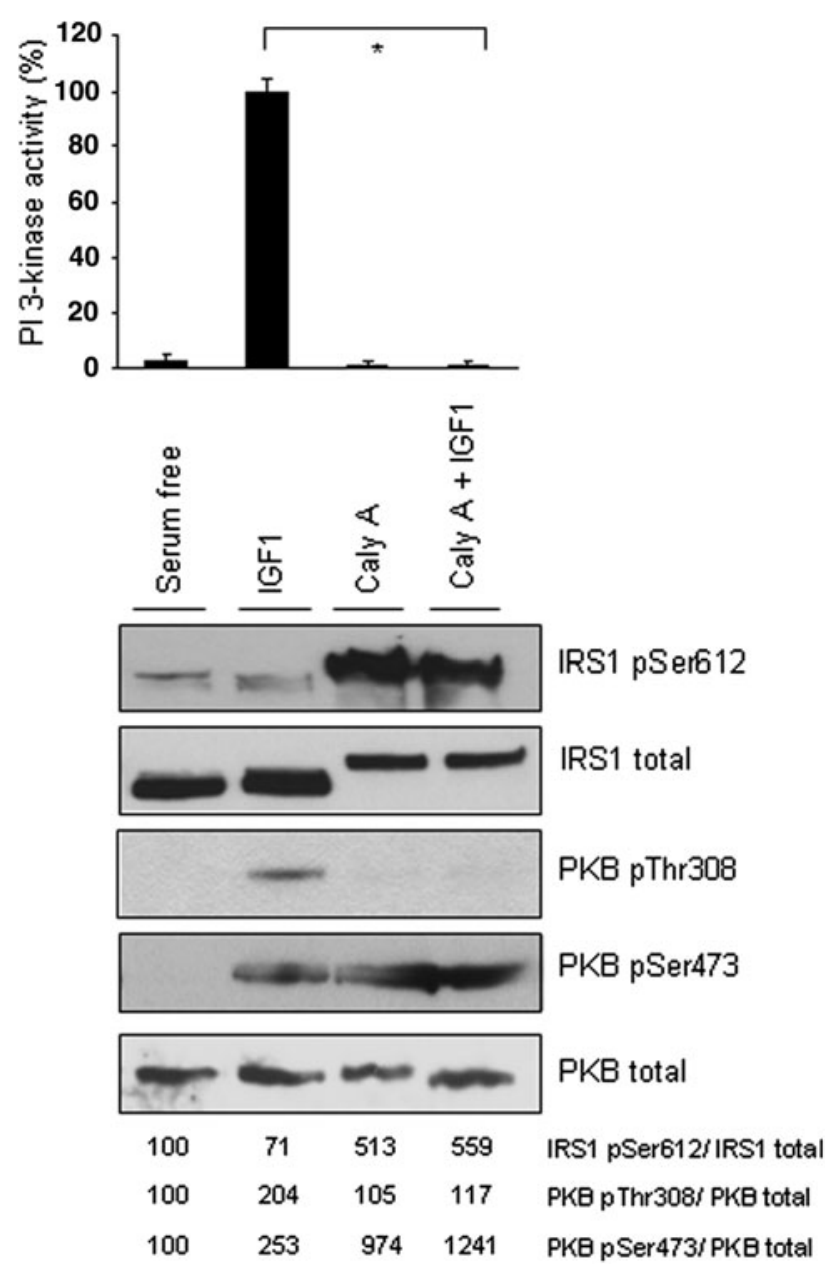

Fig. 7 Calyculin A blocks basal and IGF1-stimulated IRS1-associated PI3-kinase. HeLa cells were transferred to serum free medium in the absence (Serum free) or presence of calyculin A (Caly A) $(200 \mathrm{nM}$ for $3 \mathrm{~h}$ ), IGF1 (IGF1) $(100 \mathrm{ng} / \mathrm{ml}$ for $15 \mathrm{~min})$ or both (Caly $A+I G F 1)$. The cells were lysed and IRS1 and its associated protein(s) immunoprecipiated from the lysates and assayed for PI3-kinase activity. Activities are the average $\pm \mathrm{SD}(n=3, * P=$ 0.0016 , Student $t$-test). In addition, protein lysates were separated on $10 \%$ SDS-PAGE gels, transferred to nitrocellulose membranes and probed with indicated antibodies. Densitometrical analysis was performed and calculation of phospho/total ratios of the different kinases was performed states such as insulin resistance (reviewed in [44, 45]). For example, okadaic acid inhibited association of IRS1 and PI3-kinase stimulated by IGF1 in astrocytoma cells [43], and TNF $\alpha$ induced seryl phosphorylation of IRS1, and this effect was mimicked by okadaic acid and calyculin A [46]. The finding that calyculin A blocks IGF1-induced IRS1associated PI3-kinase activity (Fig. 7) likely dependent on a strong Ser612 phosphorylation of IRS1, probably explains why Thr308 phosphorylation and PKB activity from cells treated with IGF1 plus calyculin A were not higher than that seen with calyculin A alone (Figs. 3, 4).

\section{Conclusion}

The aim of this work was to analyse interesting observations on phosphorylation and activation PKB during stimulation with phosphatase inhibitor; first, how a strong phosphorylation of Ser473 of PKB, with apparent lack of Thr308 phosphorylation, may support PKB activation and; second, how calyculin A blocks the IGF1-dependent Thr308 phosphorylation and activation of PKB.

Our data suggest that calyculin A promotes phosphorylation of Ser473 in PKB supporting levels of PKB activation similar to those found under physiological conditions in serum-growth cells, even with basal levels of Thr308 phosphorylation. These data suggest that PKB activity is most dependent on the level of Ser473 phosphorylation rather than Thr308 phosphorylation supporting previous reports [48]. Nevertheless, our data with $\mathrm{PDK} 1^{+/+}$and PDK $1^{-/-}$mouse ES cells suggest that a basal phosphorylation of Thr308 is required for calyculin A-dependent activation of PKB. Furthermore, our data suggest that calyculin A-induced phosphorylation of Ser473 was largely blocked by LY294002 and SB-203580, indicating that both PI3-kinase/TORC2-dependent and SAPK2/p38-dependent protein kinases contributed to phosphorylation of Ser473 in calyculin A-treated cells.

Additionally, our data suggest that Ser612 phosphorylation of IRS1 by calyculin A could explain why IGF1 stimulation in the presence of calyculin A did not promote activation of PI3-kinase, phosphorylation of Thr308 and IGF1-dependent PKB activation.

Acknowledgments We thank the European Community programme "Quality of Life and Management of Living Resources" for a Marie Curie Fellowship (QLK1-CT-2000-51184), "Ministerio de Educación y Ciencia" grant BFU2006-01088/BMC and "Programa Ramón y Cajal" contract (B.O.E. 17/02/2004 ORDEN CTE/351/2004) to Mercedes Pozuelo Rubio. Also, the U.K. Medical Research Council, and pharmaceutical companies that support the Division of Signal Therapy Unit (AstraZeneca, Boehringer Ingelheim, GlaxoSmithKline, Merck-Serono and Pfizer). Thanks to Dario Alessi in the MRC Unit for PDK1-/- mouse ES cells and Agnieszka Kieloch and Richard Grier for cell culturing. 


\section{References}

1. Brazil, D. P., \& Hemmings, B. A. (2001). Ten years of protein kinase B signalling: A hard Akt to follow. Trends in Biochemical Sciences, 26, 657-664.

2. Lawlor, M. A., \& Alessi, D. R. (2001). PKB/Akt: A key mediator of cell proliferation, survival and insulin responses? Journal of Cell Science, 114, 2903-2910.

3. Scheid, M. P., \& Woodgett, J. R. (2001). PKB/AKT: Functional insights from genetic models. Nature Reviews Molecular Cell Biology, 2, 760-768.

4. Stal, O., Perez-Tenorio, G., Akerberg, L., Olsson, B., Nordenskjold, B., Skoog, L., et al. (2003). Akt kinases in breast cancer and the results of adjuvant therapy. Breast Cancer Research, 5, R37-R44.

5. Vanhaesebroeck, B., \& Alessi, D. R. (2000). The PI3K-PDK1 connection: More than just a road to PKB. Biochemical Journal, 346(Pt 3), 561-576.

6. Scheid, M. P., \& Woodgett, J. R. (2003). Unravelling the activation mechanisms of protein kinase B/Akt. FEBS Letters, 546, $108-112$.

7. Sarbassov, D. D., Guertin, D. A., Ali, S. M., \& Sabatini, D. M. (2005). Phosphorylation and regulation of Akt/PKB by the rictormTOR complex. Science, 307, 1098-1101.

8. Alessi, D. R., Andjelkovic, M., Caudwell, B., Cron, P., Morrice, N., Cohen, P., et al. (1996). Mechanism of activation of protein kinase B by insulin and IGF-1. The EMBO Journal, 15, 6541-6551.

9. Surucu, B., Bozulic, L., Hynx, D., Parcellier, A., \& Hemmings, B. A. (2008). In vivo analysis of protein kinase B (PKB)/Akt regulation in DNA-PKcs-null mice reveals a role for PKB/Akt in DNA damage response and tumorigenesis. The Journal of Biological Chemistry, 283, 30025-30033.

10. Williams, M. R., Arthur, J. S., Balendran, A., van der Kaay, J., Poli, V., Cohen, P., et al. (2000). The role of 3-phosphoinositidedependent protein kinase 1 in activating AGC kinases defined in embryonic stem cells. Current Biology, 10, 439-448.

11. O’Toole, A., Moule, S. K., Lockyer, P. J., \& Halestrap, A. P. (2001). Tumour necrosis factor- $\alpha$ activation of protein kinase B in WEHI-164 cells is accompanied by increased phosphorylation of Ser473, but not Thr308. Biochemical Journal, 359, 119-127.

12. Kumari, S., Liu, X., Nguyen, T., Zhang, X., \& D'Mello, S. R. (2001). Distinct phosphorylation patterns underlie Akt activation by different survival factors in neurons. Brain Research, 96, 157-162.

13. Yang, J., Cron, P., Thompson, V., Good, V. M., Hess, D., Hemmings, B. A., et al. (2002). Molecular mechanism for the regulation of protein kinase B/Akt by hydrophobic motif phosphorylation. Molecular Cell, 9, 1227-1240.

14. Cross, D. A., Alessi, D. R., Cohen, P., Andjelkovich, M., \& Hemmings, B. A. (1995). Inhibition of glycogen synthase kinase3 by insulin mediated by protein kinase B. Nature, 378, 785-789.

15. Alessi, D. R., James, S. R., Downes, C. P., Holmes, A. B., Gaffney, P. R., Reese, C. B., et al. (1997). Characterization of a 3-phosphoinositide-dependent protein kinase which phosphorylates and activates protein kinase $\mathrm{B} \alpha$. Current Biology, 7, 261-269.

16. Clifton, A. D., Young, P. R., \& Cohen, P. (1996). A comparison of the substrate specificity of MAPKAP kinase- 2 and MAPKAP kinase- 3 and their activation by cytokines and cellular stress. FEBS Letters, 392, 209-214.

17. Masters, J. R., Thomson, J. A., Daly-Burns, B., et al. (2001). Short tandem repeat profiling provides an international reference standard for human cell lines. Proceedings of the National Academy of Sciences of the United States of America, 98, 8012-8017.
18. Cuenda, A. (2000). Methods to assay stress-activated protein kinases. Methods in Molecular Biology, 99, 127-143.

19. Tang, X., Batty, I. H., \& Downes, C. P. (2002). Muscarinic receptors mediate phospholipase C-dependent activation of protein kinase $\mathrm{B}$ via $\mathrm{Ca}^{2+}$, ErbB3, and phosphoinositide 3-kinase in $1321 \mathrm{~N} 1$ astrocytoma cells. The Journal of Biological Chemistry, 277, 338-344.

20. Chen, D., Fucini, R. V., Olson, A. L., Hemmings, B. A., \& Pessin, J. E. (1999). Osmotic shock inhibits insulin signaling by maintaining Akt/protein kinase B in an inactive dephosphorylated state. Molecular and Cellular Biology, 19, 4684-4694.

21. Resjo, S., Goransson, O., Harndahl, L., Zolnierowicz, S., Manganiello, V., \& Degerman, E. (2002). Protein phosphatase $2 \mathrm{~A}$ is the main phosphatase involved in the regulation of protein kinase B in rat adipocytes. Cellular Signalling, 14, 231-238.

22. Pearson, R. B., Dennis, P. B., Han, J. W., Williamson, N. A., Kozma, S. C., Wettenhall, R. E., et al. (1995). The principal target of rapamycin-induced p70s6k inactivation is a novel phosphorylation site within a conserved hydrophobic domain. The EMBO Journal, 14, 5279-5287.

23. Andjelkovic, M., Jakubowicz, T., Cron, P., Ming, X. F., Han, J. W., \& Hemmings, B. A. (1996). Activation and phosphorylation of a pleckstrin homology domain containing protein kinase (RAC-PK/PKB) promoted by serum and protein phosphatase inhibitors. Proceedings of the National Academy of Sciences of the United States of America, 93, 5699-5704.

24. Gao, T., Furnari, F., \& Newton, A. C. (2005). PHLPP: A phosphatase that directly dephosphorylates Akt, promotes apoptosis, and suppresses tumor growth. Molecular Cell, 18, 13-24.

25. Vlahos, C. J., Matter, W. F., Hui, K. Y., \& Brown, R. F. (1994). A specific inhibitor of phosphatidylinositol 3-kinase, 2-(4-morpholinyl)-8-phenyl-4H-1-benzopyran-4-one (LY294002). The Journal of Biological Chemistry, 269, 5241-5248.

26. Cuenda, A., Rouse, J., Doza, Y. N., Meier, R., Cohen, P., Gallagher, T. F., et al. (1995). SB 203580 is a specific inhibitor of a MAP kinase homologue which is stimulated by cellular stresses and interleukin-1. FEBS Letters, 364, 229-233.

27. Cheng, T. J., \& Lai, Y. K. (1998). Identification of mitogenactivated protein kinase-activated protein kinase-2 as a vimentin kinase activated by okadaic acid in 9L rat brain tumor cells. Journal of Cellular Biochemistry, 71, 169-181.

28. Alessi, D. R., Caudwell, F. B., Andjelkovic, M., Hemmings, B. A., \& Cohen, P. (1996). Molecular basis for the substrate specificity of protein kinase B; Comparison with MAPKAP kinase-1 and p70 S6 kinase. FEBS Letters, 399, 333-338.

29. Taniyama, Y., et al. (2004). Role of p38 MAPK and MAPKAPK2 in angiotensin II-induced Akt activation in vascular smooth muscle cells. American Journal of Physiology Cell Physiology, 287, C494-C499.

30. Rane, M. J., Coxon, P. Y., Powell, D. W., Webster, R., Klein, J. B., Pierce, W., et al. (2001). p38 Kinase-dependent MAPKAPK-2 activation functions as 3-phosphoinositide-dependent kinase-2 for Akt in human neutrophils. The Journal of Biological Chemistry, 276, 3517-3523.

31. Dumont, F. J., \& Su, Q. (1996). Mechanism of action of the immunosuppressant rapamycin. Life Sciences, 58, 373-395.

32. DeSilva, D. R., Jones, E. A., Favata, M. F., Jaffee, B. D., Magolda, R. L., Trzaskos, J. M., et al. (1998). Inhibition of mitogen-activated protein kinase blocks $\mathrm{T}$ cell proliferation but does not induce or prevent anergy. The Journal of Immunology, 160, 4175-4181.

33. An, W. L., Bjorkdahl, C., Liu, R., Cowburn, R. F., Winblad, B., \& Pei, J. J. (2005). Mechanism of zinc-induced phosphorylation of p70 S6 kinase and glycogen synthase kinase $3 \beta$ in SH-SY5Y neuroblastoma cells. Journal of Neurochemistry, 92, 1104-1115. 
34. Parrott, L. A., \& Templeton, D. J. (1999). Osmotic stress inhibits p70/85 S6 kinase through activation of a protein phosphatase. Journal of Biological Chemistry, 274, 24731-24736.

35. Peterson, R. T., Desai, B. N., Hardwick, J. S., \& Schreiber, S. L. (1999). Protein phosphatase 2A interacts with the 70-kDa S6 kinase and is activated by inhibition of FKBP12-rapamycin associated protein. Proceedings of the National Academy of Sciences of the United States of America, 96, 4438-4442.

36. Cho, D. H., Choi, Y. J., Jo, S. A., Ryou, J., Kim, J. Y., Chung, J., et al. (2006). Troglitazone acutely inhibits protein synthesis in endothelial cells via a novel mechanism involving protein phosphatase 2A-dependent p70 S6 kinase inhibition. American Journal of Physiology, 291, C317-C326.

37. Frame, S., \& Cohen, P. (2001). GSK3 takes centre stage more than 20 years after its discovery. Biochemical Journal, 359, 1-16.

38. Rena, G., Prescott, A. R., Guo, S., Cohen, P., \& Unterman, T. G. (2001). Roles of the forkhead in rhabdomyosarcoma (FKHR) phosphorylation sites in regulating 14-3-3 binding, transactivation and nuclear targeting. Biochemical Journal, 354, 605-612.

39. Mora, A., Sabio, G., Risco, A. M., Cuenda, A., Alonso, J. C., Soler, G., et al. (2002). Lithium blocks the PKB and GSK3 dephosphorylation induced by ceramide through protein phosphatase-2A. Cellular Signalling, 14, 557-562.

40. Schubert, K. M., Scheid, M. P., \& Duronio, V. (2000). Ceramide inhibits protein kinase B/Akt by promoting dephosphorylation of serine 473. The Journal of Biological Chemistry, 275, 13330-13335.

41. Yamada, T., Katagiri, H., Asano, T., Inukai, K., Tsuru, M., Kodama, T., et al. (2001). 3-phosphoinositide-dependent protein kinase 1, an Akt1 kinase, is involved in dephosphorylation of Thr-308 of Akt1 in Chinese hamster ovary cells. The Journal of Biological Chemistry, 276, 5339-5345.

42. Yang, J., Cron, P., Good, V. M., Thompson, V., Hemmings, B. A., \& Barford, D. (2002). Crystal structure of an activated Akt/ protein kinase B ternary complex with GSK3-peptide and AMPPNP. Nature Structural Biology, 9, 940-944.

43. Batty, I. H., Fleming, I. N., \& Downes, C. P. (2004). Muscarinicreceptor-mediated inhibition of insulin-like growth factor-1 receptor-stimulated phosphoinositide 3-kinase signalling in 1321N1 astrocytoma cells. Biochemical Journal, 379, 641-651.

44. White, M. F. (2002). IRS proteins and the common path to diabetes. American Journal of Physiology, 283, E413-E422.

45. Zick, Y. (2001). Insulin resistance: A phosphorylation-based uncoupling of insulin signaling. Trends in Cell Biology, 11, 437-441.

46. Kanety, H., Feinstein, R., Papa, M. Z., Hemi, R., \& Karasik, A. (1995). Tumor necrosis factor $\alpha$-induced phosphorylation of insulin receptor substrate-1 (IRS-1). Possible mechanism for suppression of insulin-stimulated tyrosine phosphorylation of IRS-1. The Journal of Biological Chemistry, 270, 23780-23784.

47. Morino, K., et al. (2008). Muscle-specific IRS-1 Ser $\rightarrow$ Ala transgenic mice are protected from fat-induced insulin resistance in skeletal muscle. Diabetes, 57, 2644-2651.

48. Ma, K., Cheung, S. M., Marshall, A. J., \& Duronio, V. (2008). $\mathrm{PI}(3,4,5) \mathrm{P} 3$ and $\mathrm{PI}(3,4) \mathrm{P} 2$ levels correlate with $\mathrm{PKB} / \mathrm{akt}$ phosphorylation at Thr308 and Ser473, respectively; PI(3, 4)P2 levels determine PKB activity. Cellular Signalling, 20, 684-694. 